\title{
Case for diagnosis. Infective dermatitis associated with HTLV-1: differential diagnosis of atopic dermatitis*
}

\author{
Lorena Maria Lima de Oliveira ${ }^{1}$ \\ Antonio Carlos Martins Guedes ${ }^{1,2}$
}

DOI: http://dx.doi.org/10.1590/abd1806-4841.20176684

\author{
Marcos Vilela de Souza ${ }^{3}$ \\ Marcelo Grossi Araújo ${ }^{1,2}$
}

\section{CASE REPORT}

This study is a case report of a 23-year-old woman with a medical condition of a difficult to control eczema, which she has had since childhood, and a medical history of skin sepsis caused by Staphylococcus aureus (SA) in 2011. She presented erythematous-exudative plaques on the outer ear, armpits, groin, and inframammary region; flaky scalp; erythematous papules spread throughout the trunk and limbs; in addition to nasopharyngitis and scabs on the nostrils (Figures 1 and 2). The exams revealed an increased erythrocyte sedimentation rate (ESR). The culture of the secretion of the lesions revealed: Staphylococcus aureus, Klebsiella pneumoniae, and Acinetobacter baumannii multissensíveis; seropositive status for HTLV-1 (confirmed by Polymerase chain reaction- PCR). The skin biopsy showed hyperkeratosis, acanthosis, foci of spongiosis, corneal microabscesses, and perivascular and perifollicular lymphocyte infiltrate (Figure 3). The patient received cephalexin and a topical corticoid, presenting a significant improvement (Figure 4). After many recurrences, the chosen treatment was with an oral intake

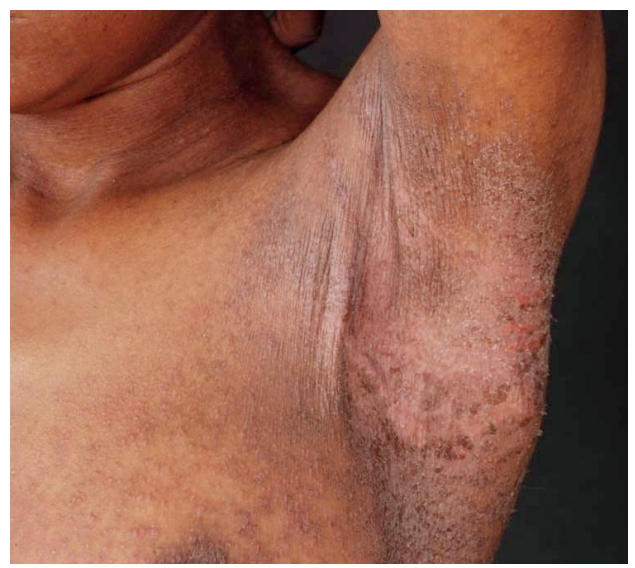

FigURE 1: Erythematous-exudative plaques in the armpit region of sulfamethoxazole-trimethoprim (every two months) and topical mupirocin for bacterial decolonization. Patient follow-up identified neurological symptoms of the difficulty to walk, urgency, and urinary incontinence.

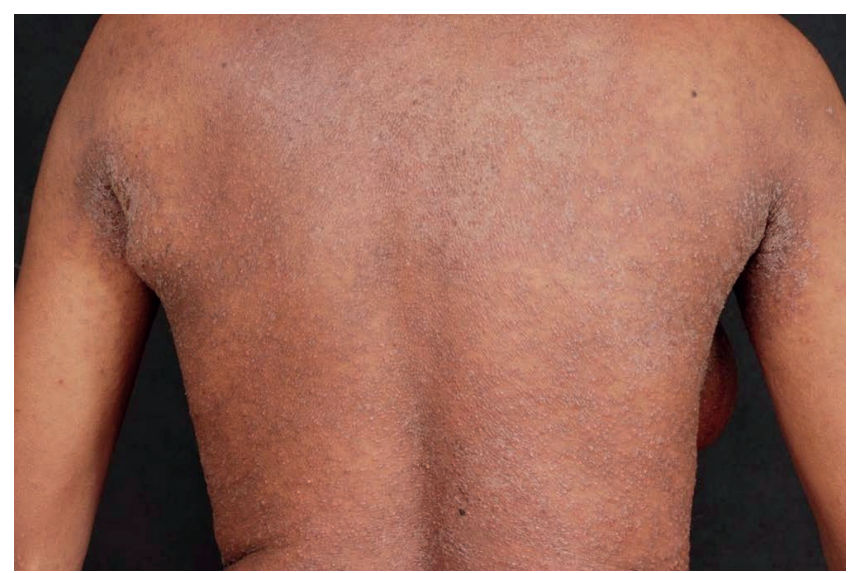

Figure 2: Papular rash on the trunk

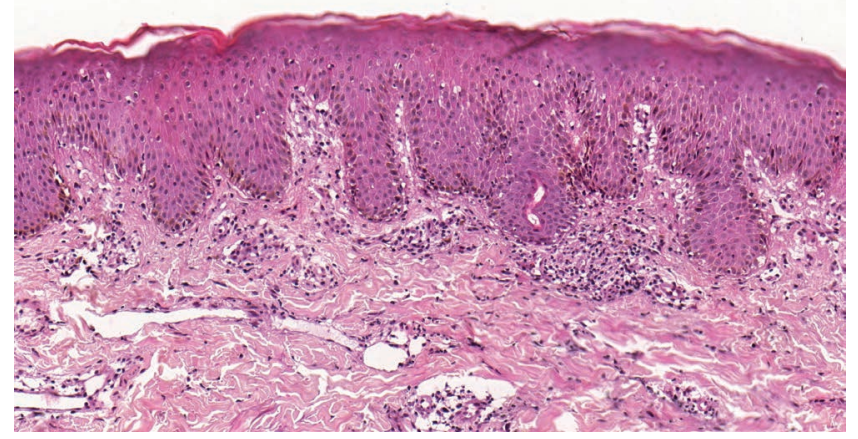

Figure 3: Skin biopsy showing hyperkeratosis, acanthosis, spongiosis, and perivascular and perifollicular lymphocyte infiltrate (Hematoxylin \& eosin, X20)

\section{Received on 05.11.2016}

Approved by the Advisory Board and accepted for publication on 30.12.2016

Work conducted at the Dermatology Service at Hospital das Clínicas, Universidade Federal de Minas Gerais (HC-UFMG) - Belo Horizonte(MG), Brazil.

Financial support: none.

Conflict of interest: none.

Dermatology Service, Hospital das Clínicas, Universidade Federal de Minas Gerais - Belo Horizonte(MG), Brazil.

Department of Clinical Medicine, School of Medicine, Universidade Federal de Minas Gerais - Belo Horizonte(MG), Brazil.

Department of Health Sciences, Universidade Federal de Lavras - Lavras (MG), Brazil. 


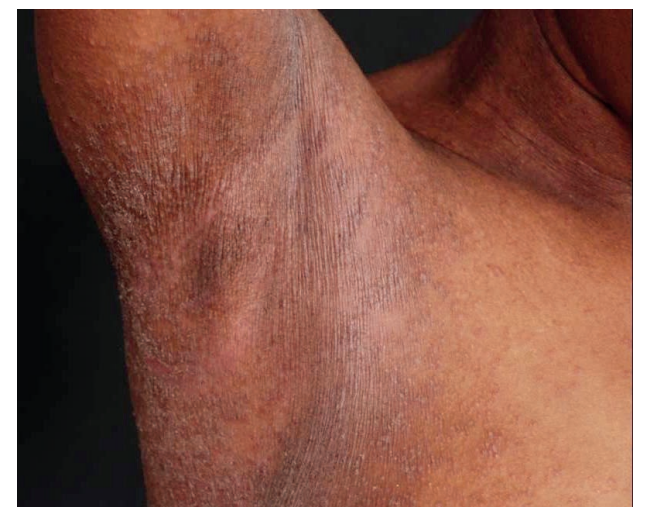

FIGURE 4: Excellent result after short application of cephalexin

\section{DISCUSSION}

Infective dermatitis, associated with HTLV-1 (DIH) appears with eczematous and exudative eruptions, associated with rhinitis and conjunctivitis. Infection by SA and/or Streptococcus $\beta$ hemolitico $(\mathrm{SBH})$ is common $(1,2)$, and tends to appear at 18 years of age, though there are reports of its appearance in early adulthood (2). In 1998, La Grenade et al. (3) set diagnostic criteria for DIH, the most important of which are: 1) Eczema on the scalp, armpits, groin, ear canal, retroauricular region, eyelids, paranasal regions, and neck; 2) Chronic rhinorrhea or scabs on the nasal vestibule; 3 ) Recurring chronic dermatitis with immediate response to antibiotic treatment and recurrence after suspension; 4) Early onset in childhood; 5) Seropositive for HTLV-1. The diagnosis is performed under four criteria, with criteria 1,3 , and 5 being mandatory. For criterion 1 , at least three sites are necessary, including the scalp and retroauricular region. The minor criteria for SA and/or SBH, papular rash, lymphadenitis, anemia, increase in ESR, hypergammaglobulinemia (IgD and IgE), and increase in CD4 and CD8.$^{2,3,4,5}$ The pathogenesis is multifactorial, though not totally known, and involves individual susceptibility, immunological deregulation, bacterial superinfection, chronic antigenic stimulation, and persistent skin inflammation. ${ }^{2,6}$ The histopathology is not diagnostic and is similar to other eczemas. The predominant lymphocyte infiltrate is $\mathrm{CD} 8+.{ }^{5}$ The main differential diagnoses include atopical dermatitis (AD) and seborrheic dermatitis (also more prevalent in patients infected by HTLV-1,6). Different from $\mathrm{AD}$, in $\mathrm{DIH}$, the lesions are more infected and more exuberant, pruritus is more intense, and nasal scabs, papular rash, and conjunctivitis can be observed. Treatment consists of antibiotics, with a good response to sulfamethoxazole-trimethoprim, cephalexin, and erythromycin. This treatment is applied for 3 to 12 months, with a full dose reestablished in cases of recurrence. ${ }^{5}$ Professionals should pay attention during follow-up, given that studies show that DIH increases the risk of leukemia and T-cell lymphomas in adults (ATL) and myelopathy associated with HTLV-1/tropical spastic paraparesia (HAM/TSP). ${ }^{2,4,5,7,8}$ The high levels of DIH antibodies and the important role of humoral immunity in HAM/TSP reinforce this relationship. ${ }^{5}$ Considering that the main transmission pathways of HTLV-1 are sexual and vertical, it is important to test relatives and partners, and offer medical advice when necessary. The neurological medical condition of this patient is compatible with HAM/TSP, and she is currently undergoing propaedeutic procedures. $\square$

\begin{abstract}
Infective dermatitis associated with HTLV-1 (IDH) is the main cutaneous marker of HTLV-1 infection. This disease occurs primarily in children and should be differentiated from other eczemas, especially from atopic dermatitis. The largest series of IDH are from Jamaica and Brazil. There are an estimated 15 to 20 million infected people in the world, and Brazil is one of the endemic regions. Studies suggest that IDH in children may be a marker for the development of T-cell leukemia/lymphoma (ATL) or myelopathy associated with HTLV-1/tropical spastic paraparesis (HAM / TSP) in adulthood.
\end{abstract}

Keywords: Dermatitis; Dermatitis, atopic; Eczema; Human T-lymphotropic virus 1; Leukemia-lymphoma, adult T-cell; Paraparesis, tropical spastic

\section{REFERENCES}

1. LaGrenade L, Hanchard B, Fletcher V, Cranston B, Blattner W. Infective dermatitis of Jamaican children: a marker for HTLV -I infection. Lancet. 1990;336:1345-7.

2. Bittencourt AL, Oliveira MF. Dermatite infecciosa associada ao HTLV -I - Revisão. An Bras Dermatol.2001;76:723-32.

3. La Grenade L, Manns A, Fletcher V, Derm D, Carberry C, Hanchard B, et al. Clinical, Pathologic, and Immunologic Features of Human T -Lymphotrophic Virus Type I-Associated Infective Dermatis in Children. Arch Dermatol. 1998:134:439-44.

4. Gonçalves DU, Proietti FA, Ribas JG, Araújo MG, Pinheiro SR, Guedes AC, et al. Epidemiology, Treatment, and Prevention of Human T-Cell Leukemia Virus Type 1-Associated Diseases. Clin Microbiol Rev. 2010;23:577-89.

5. Hlela C, Bittencourt A. Infective Dermatitis Associated with HTLV-1 mimics common eczemas in children and may be a prelude to severe systemic diseases. Dermatol Clin. 2014;32:237-48.

6. Okajima R, Oliveira AC, Smid J, Casseb J, Sanches JA Jr. High prevalence of skin disorders among HTLV-1 infected individuals independent of clinical status. PLOS Negl Trop Dis. 2013;7:e2546.
7. LaGrenade L, Morgan C, Carberry C, Hanchard B, Fletcher V, Gray R, et al. Tropical spastic paraparesis occurring in HTLV -I associated infective dermatitis. West Indian Med J. 1995;44:34-5.

8. Okajima R, Casseb J, Sanches JA. Co-presentation of human T-cell lymphotropic virus type 1 (HTLV-1)-associated myelopathy/tropical spastic paraparesisand adult-onset infective dermatitis associated with HTLV-1 infection. Int $\mathrm{J}$ Dermatol. 2013;52:63-8

\section{MAILING ADDRESS: \\ Lorena Maria Lima de Oliveira \\ Alameda Álvaro Celso, 55 - Santa Efigênia \\ 30150-260 -Belo Horizonte, MG - Brazil \\ E-mail:lorenahlima@gmail.com}

How to cite this article: Oliveira LML, Souza MV, Guedes ACM, Araújo MG. Case for diagnosis. Infective dermatitis associated with HTLV-1: differential diagnosis of atopic dermatitis. An Bras Dermatol. 2017;92(4):573-4. 